\title{
A "Pityriasis versicolor" no Estado do Amazonas
}

Ozorio J. de M. Fonsoca $\left({ }^{\circ}\right)$

Aurélia Lopes Castriilón (")

José J. Ferraroni ( ${ }^{*}$ )

\section{Resumo}

São apresentados dados de um levantamento sobre a prevalência de "Pityriasis versicolor" em 4.731 escolares de oito municípios do Estado do Amazonas com um índice de positividade de 15,18\% e comparados os resultados com a ocorrência de outras dermatomicoses.

\section{INTRODUÇÃo}

Em 1966, durante o Simpósio sobre a Biota Amazônica, Moraes \& Ferreira (1967) apresentaram um trabalho onde registraram as micoses humanas mais freqüentes na região amazônica. Os autores sumarizaram os achados micológicos, estabelecendo um quadro micopatológico baseado em observações e pesquisas, muitas delas inéditas até hoje. Mais recentemente, Moraes (1973) fez uma apresentação de 696 casos de micoses superficiais encontradas em Manaus no período de 1961-1968, mostrando a etiologia dessas infecções, localização corporal' das "tinhas" e distribuição por faixa etária, sem contudo fazer qualquer referência ao problema da "Tinea versicolor".

Êsses dois trabalhos parecem ser os úni$\cos$ que abordam o problema das micoses superficiais no Estado do Amazonas.

Por se constituirem infecçōes que não afetam o estado geral do paciente, as dermatomicoses não são encaradas como doenças e suas vitimas, seja pela falta de recursos financeiros, seja pela falta de assistência médica no interior do Estado, vivem com essas infecções sem lhes dar importância ou procurando a cura nos produtos naturais da floresta que a crendice e a tradição popular consagraram como "ótimo remédio para impinge".
Entre as micoses superficiais, a "Pityriasis versicolor", chamada regionalmente de "pano branco", apresenta a mais alta ocorrência, sendo no entanto tida como "caiacanga", denominação dada no Norte às doenças sem importância (Vianna, 1967).

$\mathrm{Na}$ tentativa de conhecer a ocorrência dessa dermatomicose no Estado do Amazonas, levou-se a efeito um levantamento entre os escolares de curso primário de algumas localidades do Estado, no período de 1971 a 1972. A idéia inicial de levantar dados sobre todas as dermatofitoses foi prejudicada pela falta de condiçōes de trabalho com culturas fúngicas no interior. O diagnóstico de micose para os problemas dermatológicos limitou-se ao exame direto do material retirado das lesões, razão pela qual a etiologia das outras "tinhas" não foi estabelecida, ficando os dados carentes de importância do ponto de vista micológico, sendo apresentados apenas para efeito de comparação.

\section{MATERIAL E MÉTOdos}

A escolha das localidades onde se levou a efeito o levantamento fez parte do esquema estabelecido para o desenvolvimento de outros dois programas de pesquisa. Foram observados os escolares nos municípios de Benjamin Constant e Manacapuru, no rio Solimões; Itacoatiara, no rio Amazonas; Maués, no rio Maués; Tapauá, Canutama e Lábrea, no rio Purus, e Manaus no rio Negro (Mapa).

A impossibilidade de levantar a população escolar total desses municípios amazonenses, em virtude das enormes distâncias e da dificuldade de meios de transporte, fez com que apenas as sedes municipais fossem estudadas, exceção feita à Benjamin Constant,

(*) - Instituto Nacional de Pesquisas da Amazônia, Manaus. 
onde se optou por Tabatinga, núcleo militar de fronteira, onde as condições de trabalho para os outros dois programas eram mais favoráveis.

Embora năo se tenha podido obter daios concretos sobre o número de escolares dos

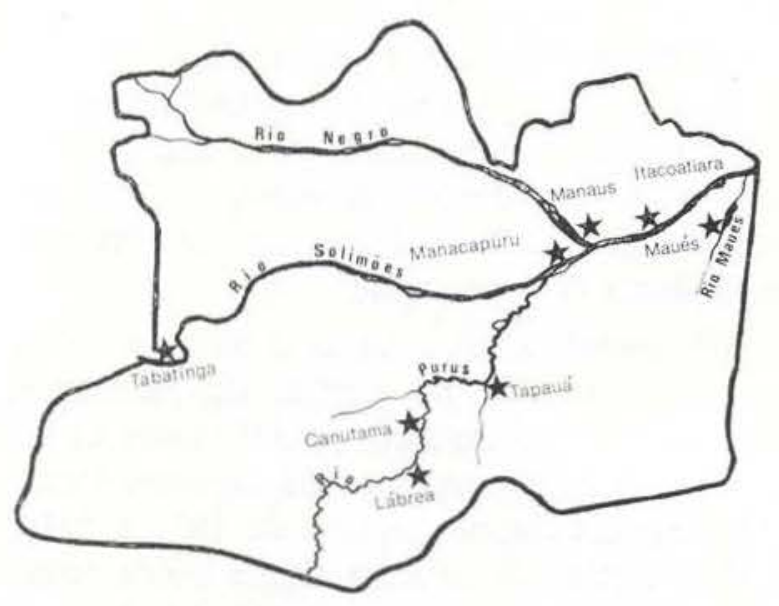

Mapa das localidades estudadas

\section{GRÁFICO I}

Porcentagem de individuos com

"Pityriasis versicolor" por grupo etário

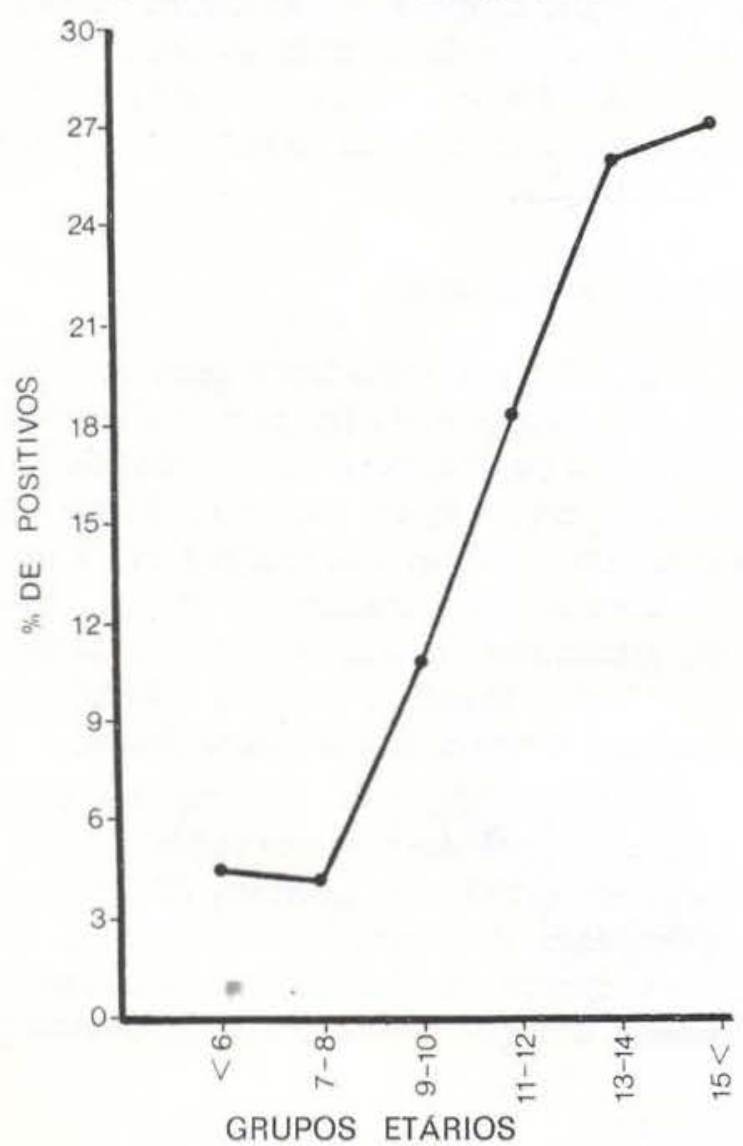

cursos primários das localidades estudadas, calcula-se que em Tapauá, Canutama, Lábrea e Tabatinga a amostra represente 80 a $90 \%$ da população escolar de primeiro ciclo. Em Maués, Itacoatiara e Manacapuru a amostra deve atingir 20 a $30 \%$ e, em Manaus, aproximadamente $20 \%$.

O método consistiu no exame superficial dos estudantes, retirando-se material com fita Durex (método de Porto) das lesões suspeitas de "Tinea versicolor". Das outras afecções suspeitas de dermatomicose, foram retiradas escamas de pele, unhas e pelos para microscopia em preparação com $\mathrm{KOH}$ a $20 \%$. O exame microscópico das lâminas dava o diagnóstico, pela presença de filamentos micelianos de dermatófitos ou das estruturas micromorfológicas típicas da Malassezia furfur.

\section{Resultados}

Os resuitados são apresentados nas Tabelas e Gráficos subseqüentes.

GRÁFICO II

Distribuiçāo percentual do to:al de casos positivos, por grupo etário

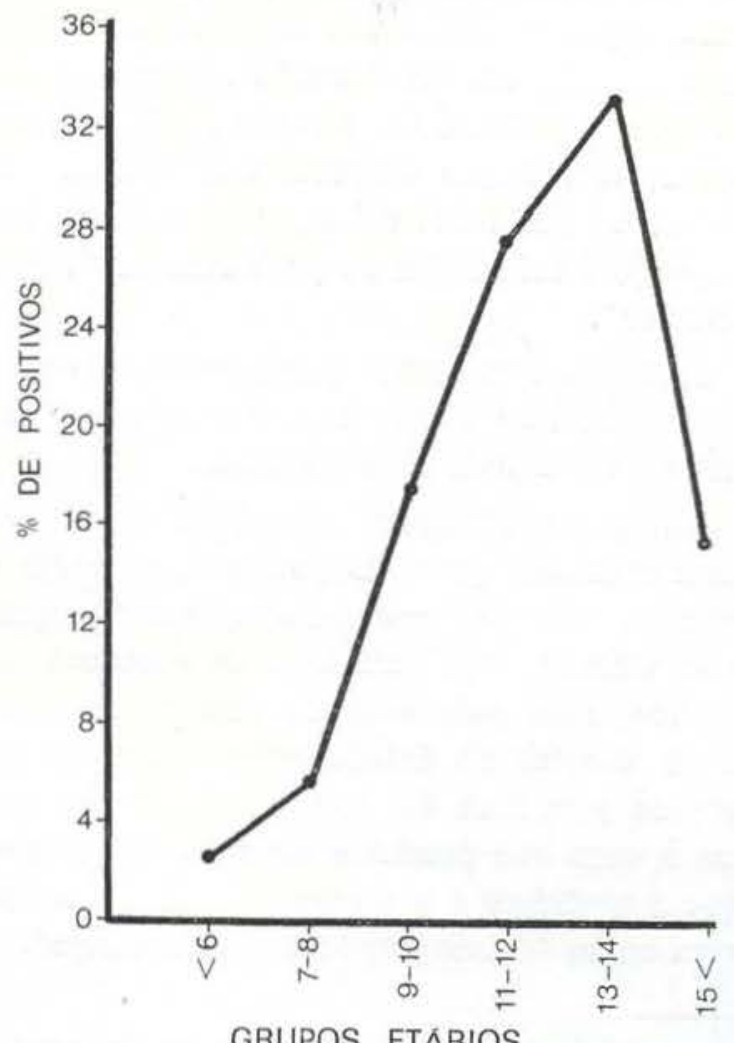

GRUPOS ETÁRIOS 


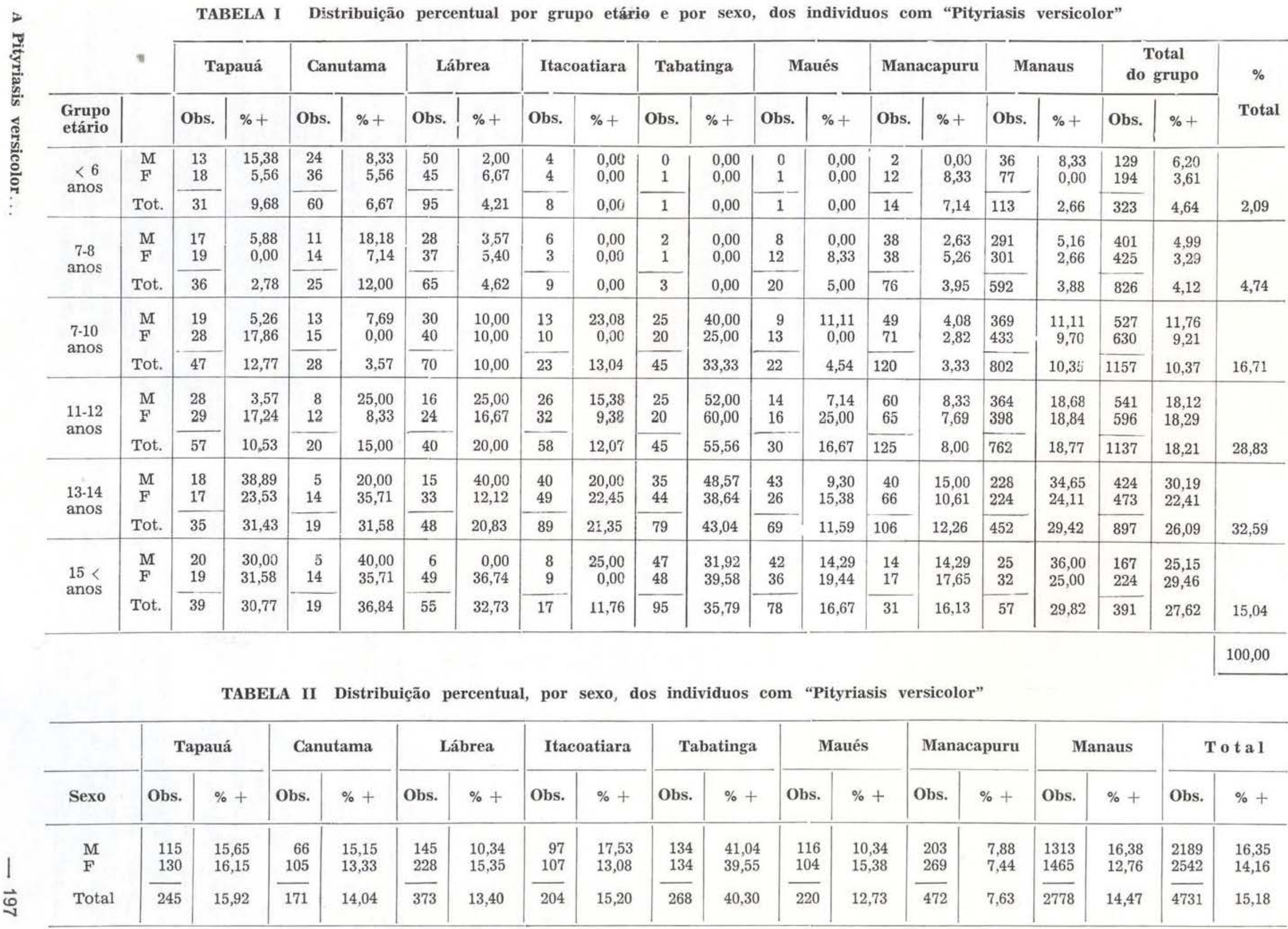




\section{TABELA III}

Relação percentual de incidência entre "Pityriasis versicolor" e as outras dermatomicoses, em seis localidades $(*)$

\begin{tabular}{l|r|r|r}
\hline Localidades & $\begin{array}{r}\text { N.॰ } \\
\text { Obs. }\end{array}$ & $\begin{array}{c}\text { \% c/ } \\
\text { Pityriasis } \\
\text { versicolor }\end{array}$ & $\begin{array}{c}\text { \% c/outras } \\
\text { dermato- } \\
\text { micoses }\end{array}$ \\
\hline Tapauá & 245 & 15,92 & 9,39 \\
Canutama & 171 & 14,04 & 15,79 \\
Lábrea & 373 & 13,40 & 11,26 \\
Itacoatiara & 204 & 15,20 & 0,98 \\
Manacapuru & 472 & 7,63 & 1,91 \\
Manaus & 2778 & 14,47 & 4,97 \\
\hline \multicolumn{1}{c}{ Total } & 4243 & 13,72 & 5,68 \\
\hline
\end{tabular}

(*) Nôo foram coletados dados de Maués e Tabatinga.

\section{COMENTÁRIOS E CONCLUSŌES}

Pelos dados apresentados, conclui-se que a "Tinea versicolor" é a infecção micótica e talvez o problema dermatológico de maior ocorrência no Estado do Amazonas. A insuficiência de literatura a respeito de outras dermatoses na região impedem uma comparação mais nítida, extraindo-se esta conclusão, de informaçōes pessoais de dermatologistas que atuam na área.

De qualquer forma a "Pityriasis" por muito tempo ainda será considerada doença sem importância, ficando apenas para as classes sócio-econômicas mais elevadas, por problemas de estética, a procura de remédio para esta infecção.

Embora restrições sociais aos infectados com a Malassezia furfur sejam raras, pode-se afirmar que elas existem em algumas localidades, principalmente onde outros problemas dermatológicos estigmatizantes são de grande incidência.

Numa análise dos resultados, verifica-se que não existem, de um modo geral, diferenças significativas entre os municipios estudados, exceção feita à Tabatinga cujos índices de positividade atingem $40,30 \%$ do total de indivíduos examinados, sendo a maior ocorrência, na faixa etária dos 11 aos 12 anos (Tabela 1). O percentual mínimo de indivíduos infectados $7,63 \%$, aparece em Manacapuru, cidade do baixo Solimões (Mapa), onde o maior índice está na faixa dos 15 anos em diante, com $16,13 \%$. As demais localidades mantêm mais ou menos as mesmas taxas de positividade, variando de $12,73 \%$ em Maués a 15,92\% em Tapauá.

No gráfico I, apresentam-se os percentuais de incidência da "Pityriasis versicolor" nas faixas etárias estudadas, mostrando a curva, uma tendência máxima para a extremidade. No gráfico II, a distribuição percentual do total de indivíduos infectados, apresenta uma curva moderadamente assimétrica com desvio à esquerda, ficando o maior índice na faixa etária dos 13 aos 14 anos.

No cômputo geral, dos 4.731 estudantes examinados, a taxa de $15,18 \%$ representa um alto indice de infecção pela Malassezia furfur, fungo responsável pelo mais freqüente problema micológico entre os escolares do Estado do Amazonas.

\section{SUMMARY}

The results of a survey of the incidence of "Pityriasis versicolor" are reported here. The survey was of 4,731 school-children from eight municipalities in the State of Amazonas, Brasil. "Pityriasis versicolor" was found to be present in $15,18 \%$ of the children. This rate of incidence was compared with that of other micosis of the skin in the same town.

\section{BIBLIOGRAFIA CITADA}

MorAes, M. A. P. \& FerReIRA, J. L. DE S.

1967 - Micoses superficiais e- profundas na Amazonia. Atas do Simpósio sôbre a Biota Amazonica, 6 (Patologia): 189-202.

Moraes, M. A. P.

1973 - Dermatófitos no Estado do Amazonas. Acta Amazonica, 3(1): 65-69

VIANNA, C.M.

1967 - Glossário popular em Semiótica (Coletânea em localidade amazônica). Atas do Simposio sôbre a Biota Amazonica, 6 (Patologia): 285-301. 